\title{
The Influence of Feeding Practices On Nutritional Status of Children Less Than 2 Years In Heliwa District, Mogadishu
}

\author{
Hassan Abdullahi Dahie \\ Faculty of Health Science \\ Mustaqbal University, Mogadishu-Somalia \\ SoS Community Nursing School, Mogadishu-Somalia. \\ Abdullahi Ali Heyle \\ SOS Community Nursing School, Mogadishu-Somalia
}

\begin{abstract}
Background: Adequate nutrition during infancy and early childhood is fundamental to the development of each child's full human potential. A child who has adequate nutrition performs better in school, grows into a healthy adult and in turn gives his/her children a better start in life. However, for a child to have an adequate nutrition basically depends on the feeding practices offered by mothers or care-takers (UNICEF, 2007). SDG 2 is targeted at improving nutrition, ending hunger and achieving food security. Objective: To determine the influence of feeding practices on nutritional status of children under two years in Heliwa District, Mogadishu, Somalia 2016. Methodology: Community-based cross sectional study design. Data were collected by using pretested questionnaires. A total of 403 mothers and their children were included in the study. A systematic random sampling and simple random sampling were used to select the households to participate and starting household respectively. Data were captured using EpiData-3.0, excel and ENA, analysed with STATA-12. Univariate and bivariate analysis were carried out to see significant association, $\mathbf{P}$ value $<0.05$ was considered as significant association. Results: The prevalence of underweight, stunting and wasting were $30.7 \%, 27.5 \%$ and $28.5 \%$ respectively. Children whose fathers were unemployed were 2 times more likely to develop wasting than employed (OR 2.0, 95\%CI 1.42-2.88). Furthermore, children who were introduced complementary foods late after six months were more likely to develop underweight and wasting [(OR 1.59 95\%CI 1.22-2.92) and (OR 1.40 95\%CI 1.09-2.43)] respectively. Conclusion and recommendation: There was high prevalence of malnutrition (wasting, stunting and underweight) among children less than 2 years in the district. There is a need for intervention programs. Midwives and nurses should encourage mothers to initiate breastfeeding in the first hour after delivery.
\end{abstract}

Key words: Malnutrition, Underweight, Stunting, Wasting, Exclusive breastfeeding, Complementary feeding.

\section{INTRODUCTION}

Adequate nutrition during infancy and early childhood is fundamental to the development of each child's full human potential. A child who has adequate nutrition performs better in school, grows into a healthy adult and in turn gives his/her children a better start in life. However, for a child to have an adequate nutrition basically depends on the feeding practices offered by mothers or care-takers (UNICEF, 2007). Sustainable Development Goals is targeted at improving nutrition, ending hunger and achieving food security.

However, in the developing countries 146 million children under-5 suffer from under-nutrition which is one of the main factors that causes malnutrition (UNICEF, 2007). In Africa, 
malnutrition continues to contribute to half of the 9.7million annual child deaths and is a leading cause of diseases and disabilities in children (WHO, 2012; UNICEF, 2007). In SubSaharan Africa, four million children die from preventable diseases annually of which $60.0 \%$ is as a result of malnutrition.

The immediate consequences of poor nutrition during the formative years of a child include significant morbidity, mortality, delayed mental and motor development. In the long-term, early nutritional deficits are linked to impairments in intellectual performance; work capacity, reproductive outcomes and overall health during adolescence and adulthood (Kramer et al, 2013). Thus, the cycle of malnutrition continues, as the malnourished girl child faces greater odds of giving birth to a malnourished, low birth weight infant when she grows up (Kramer et al, 2013).

Poor breastfeeding and complementary feeding practices, coupled with high rates of infectious diseases, are the principal proximate causes of malnutrition during the first two years of life (Kramer et al, 2013).

Current guidelines for infant feeding, developed jointly by the World Health Organization and the United Nations Children's Fund in 2003, emphasize exclusive breastfeeding for the first six months of life and the subsequent addition of appropriate complementary foods to meet the increasing energy requirements for infant growth (UNICEF/WHO, 2003). Continued breastfeeding is recommended for the first two years and beyond. These guidelines also emphasize the importance of continued feeding during illness in order to maintain the infant's immune and nutritional status (PAHO/WHO, 2003).

Breast milk alone is the ideal nourishment for infants for about the first six months of life. It contains all the nutrients, antibodies, hormones and antioxidants an infant needs to thrive. It protects babies from diarrhoea and acute respiratory infections, stimulates their immune systems, response to vaccination and confers cognitive benefits as well (Oddy, 2011).

Continued breastfeeding to two years, accompanied by appropriate complementary feeding, maintains good nutritional status and continues to help prevent diarrhoea. It has been estimated that improved breastfeeding practices could save some 1.5 million children a year. Yet few of the 129 million babies born each year receive optimal breastfeeding and some are not breastfed at all (WHO, 2008).

Besides, proper complementary feeding reduces mortality by $6 \%$ yet in most developing countries the complementary feed given to these infants and young children are usually contaminated and inadequate (WHO, 2008). For the reduction by two-thirds of under-five mortality to be achieved, there is the necessity for rapid improvement of feeding of these children. These feeding practices constitute one of the most neglected determinants of young child malnutrition in spite of their important role in growth pattern of children (Childinfo, 2009).

Somalia is characterized by some of the worst Infant and Young Child Feeding (IYCF) and micronutrient indicators in the world. According to the FSNAU Micronutrient Survey (2009), the prevalence of exclusive breastfeeding in Somalia is $5.3 \%$ while the prevalence of early initiation is $23.4 \%$. Nearly three quarters (73\%) of children under two are anaemic, almost half of all women and $60 \%$ of under-fives (Montani and Omwega, 2002). 


\section{STATEMENT OF THE PROBLEM}

Breastfeeding is an unequalled way of providing ideal food for the healthy growth and development of infants; it is also an integral part of the reproductive process with important implications for the health of mothers. Review of evidence has shown that, on a population basis, exclusive breastfeeding for 6 months is the optimal way of feeding infants. Thereafter infants should receive complementary foods with continued breastfeeding up to 2 years of age or beyond (WHO, 2008).

However, according to the FSNAU Micronutrient Survey (2009), the prevalence of exclusive breastfeeding in Somalia is $5.3 \%$ while the prevalence of early initiation is $23.4 \%$. Nearly three quarters (73\%) of children under two and $60 \%$ of under five are anaemic. Bottle feeding culture even immediately after birth of the baby now predominates over breastfeeding the baby in the first hour of life. One typical of such areas is Heliwa district. For the decade the nutritional status of the children under 5 years in this district has been in fluctuation of deterioration at different rates. However, there are no correct and comprehensive records on underweight, stunting and wasting. This study explored the role of infant feeding practices in the aetiology of malnutrition in Heliwa, since it is believed that growth retardation is very high among children under two years (critical stage) in this district.

Therefore, if this continues many children would develop malnutrition and growth retardation, since one of the most critical factors for children's health and development is their nutritional status. Children who are undernourished are less able to fight off infections and more likely to die young.

\section{General Objective}

\section{OBJECTIVES}

To determine the feeding practices in relation to nutritional status of children under two years.

\section{Specific Objectives}

1. To determine the nutritional status of children under two years in Heliwa District.

2. To study the breastfeeding practices among mothers with children under two years in Heliwa District.

3. To identify the complementary feeding patterns among mothers with children under two years in Heliwa District.

4. To establish the relationship between the feeding practices of children under two years and their nutritional status in Heliwa District.

\section{Research Hypothesis}

There is an association between feeding practices and nutritional status of children under two years of age.

\section{LITERATURE REVIEW}

In the first moments, months and years of life, every touch, movement and emotion in a young child's life translates into an explosion of electrical and chemical activity in the brain, as billions of cells are organizing themselves into networks requiring trillions of synapses between them. These early childhood years are when the child needs balanced diet usually through good feeding practices (i.e. exclusive breastfeeding in the first six months and complementary feeding beyond) (Engle, 2007). 
Nutritional status generally refers to whether or not the individual is eating the correct amounts and types of nutrients (Engle, 2007). Nutritional status can be determined by assessing several factors, including body composition and appearance, blood levels, existing conditions, and issues that may impact your access to or ability to consume and absorb food. Nutritional status is influenced by the amount of each essential nutrient that you consume (Engle, 2007).

The immediate determinants of child nutritional status manifest themselves at the level of the individual human being. They are dietary intake (energy, protein, fat, and micronutrients) and health status. These factors themselves are interdependent. A child with inadequate dietary intake is more susceptible to disease. In turn, disease depresses appetite, inhibits the absorption of nutrients in food, and competes for a child's energy.

The immediate determinants of child nutritional status are, in turn, influenced by four underlying determinants manifesting themselves at the household level. These are socioeconomic and demographic characteristics, healthy environment, proper sanitary conditions and infant and young child feeding practices. The underlying factors are also interdependent to each other as depicted in the dashed red arrows which will not be focused in the analysis except their influence on nutritional status of children.

Nutrition is assessed by two types of methods; direct and indirect. The direct methods deal with the individual and measure objective criteria, while indirect methods use community health indices that reflect nutritional influences (SCN, 2013).

Recommended anthropometric indices used to characterize malnutrition include: Weight-forHeight (to assess wasting); Height-for-Age (to assess stunting); Weight-for-Age (to assess underweight); Body mass index (BMI) calculation for children older than 2 years and all adults. For children younger than 2 years of age, growth indicators should be compared to WHO 2standardized growth references while Center for Disease Control and Prevention/National Center for Health Statistics (CDC/NCHS) references may be used for those over 2 years of age (Oireri, 2006).

Anthropometric examination is an almost mandatory tool in any research to assess health and nutritional condition in childhood. Physical measurements like body weight, height, circumference of arm and calf, triceps skin fold of children have been extensively used to define health and nutritional status of communities. Based on the age, body weight and height, a number of indices such as height-for-age and weight-for-height have been suggested. The children are classified using three categories: 'underweight' (low weight-for-age), 'stunting' (low height-for-age) or 'wasting' (low weight-for-height). Low anthropometric values are those more than 2 SD away from the standard of CDC 2000 (Centers for Disease Control and Prevention) (Omanga and Okeyo, 2015).

Stunting is defined as a low height-for-age for children, and it measures the past (chronic) child undernutrition. Children with z-scores $<-2.00$ are said to be stunted and those $<-3.00$ severely stunted. Wasting is defined as low weight-for-height for children, and it is a measure of current or acute undernutrition. Children with z-scores $<-2.00$ are said to be wasted. Underweight is defined as low weight-for-age and it reflects past (chronic) and present (acute) undernutrition. Children with z-scores $<-2.00$ are said to be underweight (Sphere Project, 2004).

However, according to Mark (2007) the nutritional status of children does not only directly reflect the socioeconomic status of the family and social wellbeing of the community, but also 
the efficiency of the health care system, and the influence of the surrounding environment. Nevertheless inappropriate feeding practices are a major cause of the onset of malnutrition in young children. Children who are not breastfed appropriately have repeated infections, grow less well, and are almost six times more likely to die by the age of one month than children who receive at least some breast milk.

\section{Breastfeeding Practices}

The recognition of breastfeeding as the most favourable method of infant feeding has spread worldwide (Godfrey and Lawrence, 2010). The numerous maternal and child health benefits of breastfeeding have been widely acknowledged, with an increase in the awareness of the advantages of breast milk over formula (Childinfo, 2009).

Breast feeding practice especially exclusive breast feeding (EBF) is a major determinant of child growth and development. In Somalia, as believed most women breastfeed their infants for long periods, but many introduce alternative feeding too early in life. More than one third of child deaths occurs during the first fragile month of life while early breastfeeding provides critical nutrients, protects infants against deadly diseases and fosters growth and development (Childinfo, 2009)

Breastfeeding practices are determined by various factors including cultural norms, beliefs, mother's knowledge and previous experience (Amal et al., 2007; Nkala and Msuya, 2011). These factors operate differently across communities and therefore, do affect child health to varying degrees.

Breastfeeding protects babies from many diseases and reduces the severity of their symptoms. Among these diseases we can mention respiratory infections, gastrointestinal infections and diarrhea. Lower incidences of these diseases were reported in infants fed with breast milk. Sphere Project (2004) showed that breastfeeding longer than 12 months is effective in reducing the risk of myopia in six to seven years old children. A review of several studies showed that breast milk contains bacteria that are disinfectants and strengthen the immune systems of the infants' bodies. This was supported Oireri (2006) the high impact of breastfeeding on growth and health of skeletal system of children, compared to other nutritional methods of breast feeding.

Ibrahimzadekar (2012) showed that exclusive breast feeding up to six months and its continuation until 18 months is effective in reducing the risk of childhood obesity. Some studies have shown that breastfeeding and increased breastfeeding duration is an important factor in reducing obesity and overweight in children. But, Shields et al. (2014) did not find an independent relationship between decreased overweight and obesity and breastfeeding. Instead, they found that other factors, including genetic and environmental factors are involved in this relationship. However, in another study, Kramer et al. (2011) showed that breastfeeding had no effect on reducing obesity and overweight. Ijarotimi (2012) study of 200 breastfeeding mothers concluded that there was no significant relationship between breastfeeding mothers and their BMI. Burke et al. (2015) suggested in a study that children that are breastfed for less than four months are more likely to develop obesity and overweight, or had increased obesity and overweight, compared to children who had been breast fed more than 4 months.

Several studies also supported the protective effect of breastfeeding against the development of type I diabetes (Burke, 2015). Meyer (2012) showed in their study of 167 adolescents that breastfeeding is a protective factor against type II diabetes in adolescents. In some studies 
linking breastfeeding with reduced risk of type II diabetes has been emphasized. According to Villegas and Stuebe (2013) argued that breastfeeding protects both mother and child from type II diabetes. They have also shown that breastfeeding protects mother from hypertension; however other studies did not report such an association. They also found that the risk of developing type II diabetes in mothers who tend to breastfeed their babies less than a month is more than mothers who do not.

In a case-control study of 400 cases and controls conducted by Schnooyi et al. (2009) it was shown that breastfeeding up to six months is associated with a reduced risk of asthma in 2-8year old children. Another study showed that vitamin C found in breast milk reduces allergy in children. Kramer et al (2011) study of 17046 children did not confirm the effects of long-term breast-feeding in reducing asthma and allergy. On the other hand, Silvers et al. (2013) reported a significant relationship between breastfeeding and lower respiratory disorders, especially wheezing. Silvers et al. (2013) showed that exclusive breastfeeding may reduce asthma and allergies at age six years old.

In Somalia, a KAP study found that knowledge; attitude and practices on breastfeeding are mainly controlled by culture through maternal grandmothers and other elderly women in the community, and are generally unsatisfactory. Most children are put on breast 2-3 days after delivery and the colostrum is not fed to children by majority of mothers as it is considered heavy, thick, course, dirty, toxic, and harmful to children's health. Breastfeeding is however acceptable to all mothers and their networks and almost all children breastfeed on demand (ACF, 2006).

\section{Initiating breastfeeding}

The initiation of breastfeeding within one hour of birth has numerous nutritional and immunological benefits and has been found to reduce neonatal mortality.

Breastfeeding is a foundation practice for appropriate care and feeding of newborn infants and has nutritional, immunological, developmental, psychological, social, economic and environmental benefits for infants, mothers, families and society. Provision of mother's breast milk to infants within one hour of birth is referred to as "Early Initiation of Breast Feeding (EIBF)". This practice ensures that the infant receives colostrum which is rich in immunoglobulin (Ig) and other bioactive molecule, including growth factors that are important for nutrition, growth and development of newborn infants and also for passive immunity (Kramer, 2011).

Clemens (2009) in a cohort study done in rural Egypt found that EIBF was associated with marked reduction in the rate of diarrhea throughout the first 6 months of life possibly because of the salutary effects of human colostrum. Furthermore, EIBF enhances "Maternal-infant Bonding" defined as the development of the core relationship between mother and child which begins in early infancy and continues over the next few years with tremendous implications for the child's future development (Ijarotimi, 2012). In addition, infants breastfed within 30 minutes of birth are likely to remain breast fed for a longer period of time. Research findings in Ghana and Nepal, showed that approximately one-fifth of all neonatal deaths could be avoided if breastfeeding were initiated within the first hour of life for all newborns. Furthermore, EIBF is also beneficial to mothers as it decreases postpartum bleeding and is associated with rapid uterine involution due to increase concentrations of oxytocin (Ibrahimzadekar, 2012). 
A study conducted among 10,000 infants in rural Ghana revealed that neonatal mortality could be reduced by $24 \%$ if $99 \%$ of infants initiated breastfeeding on day one of life and 31\% if $99 \%$ of infants initiated breastfeeding within the first hour, saving 867,000 and 1,117,000 (WHO/UNICEF, 1990).

In 38 out of 60 high mortality countries, the average proportion initiating breastfeeding within the first hour was $36 \%$ which predicted that 1 million neonatal lives could have been saved worldwide out of 4 million neonatal deaths (WHO/UNICEF, 1990). A study carried out on childhood feeding practices in Ethiopia revealed that $99.8 \%$ of the children were initially breastfed (Dubois and Girard, 2013).

Early or timely initiation of breastfeeding, specifically within $1 \mathrm{~h}$ of birth, refers to the best practice recommendation by the World Health Organization (WHO). A recent systematic review and meta-analysis revealed that breastfeeding initiation after the first hour of birth doubles the risk of neonatal mortality. In specific countries, initiating within $1 \mathrm{~h}$ reduced deaths by $19 \%$ in Nepal and $22 \%$ in Ghana. The evidence, drawn from meta-analysis and over 63 developing countries, shows that early initiation of breastfeeding prevents newborn infections, averts newborn death due to sepsis, pneumonia, diarrhoea and hypothermia, and facilitates sustained breastfeeding. In South Asia, merely $41 \%$ of newborns are breastfed within 1 hour of birth. Several South Asian countries have some of the worst early initiation of breastfeeding practices in the world; the rates in Pakistan, India, Bangladesh and Nepal are only 29, 41, 47 and $45 \%$ respectively. Insufficient attention is afforded to the public health issue of early or timely initiation of breastfeeding, and the causes of poor practice, even though this preventive intervention is highly cost-effective.

Breastfeeding research predominantly focuses on exclusive breastfeeding to the age of 6 months and other infant and young child feeding (IYCF) indicators. Existing systematic literature reviews on early initiation primarily draw on evidence from developed countries and on the effect of skin-to-skin contact on breastfeeding rates. It is important to understand the factors associated with delayed breastfeeding initiation and the existing barriers and facilitators to early initiation in order to design and deliver effective strategies to improve the practice and accelerate progress in newborn survival (WHO/UNICEF, 1990).

\section{Exclusive breastfeeding}

Studies have shown that infant weight and height gains during early postnatal life are influenced by infant feeding practices (Picciano et al., 2001). Several guidelines have been developed to promote appropriate infant feeding including the optimal duration of exclusive breastfeeding (EBF). The World Health Organization recommends EBF for the first six months of life (WHO, 2008).

This recommendation is based on evidence of the importance of good nutrition in the early months of life and the role it has in achieving good health. The benefits include prevention of disease and infection in childhood (Dirorimwe, 2007) and improved cognitive and motor skills development (WHO, 2008).

Breast milk provides all the energy and nutrients that an infant needs during the first six months yet barely one in three infants is exclusively breastfed during the first four months of life (WHO, 2008).

Exclusive breastfeeding, which is, giving only breast milk for the first six months of life, is crucial to preventing the deaths of newborns and infants. This practice can prevent an 
estimated 1.3 million death each year by protecting against diarrhoea, pneumonia and hastens recovery during illness (WHO, 2008). Unfortunately, many people are unaware of breast milk benefits and in many of the world's poorest countries, water and other liquids are added to the baby's diet for the first months of life risking infection from harmful bacteria and other pathogens $(\mathrm{MoH}, 2005)$. A cross study done in Northern Senegal confirms that water was introduced to $85 \%$ of the infants during the first 3 months of their lives even though there was no significant association between the early introduction of water and wasting and stunting of the infants. However, stunting was associated with age and drinking of tap water (WHO, 2009). Study conducted by UNICEF in Somaliland in 2014 revealed that exclusive breastfeeding under 6 months is $12.8 \%$ and Somaliland has rather better EBF indicator than South Central Somalia.

In Somalia, it is believed that exclusive breastfeeding (EBF) does not exist in most parts of South Central Zone (SCZ). To majority of the caregivers and their social support network, EBF means feeding children on breast milk and water with some sugar alone without any soft or solid foods. Breastfeeding continues alongside complementary foods because breast milk alone is believed to be inadequate for the child (FSNAU, 2007).

Exclusive breastfeeding for at least the first six months of life is recommended by UNICEF and the World Health Organization. Breast milk provides all the nutrients newborns need for healthy development and also provides important antibodies against common childhood illnesses. Exclusive breastfeeding also prevents babies from ingesting contaminated water that could be mixed with infant formula.

The difference between breastfeeding and formula feeding is tremendous: Breastfed children have at least a six-fold greater chance of survival in the early months than non-breastfed children. Still, many Somali women do not exclusively breastfeed; instead feeding their infants with camel's milk, tea or water in addition to breast milk (UNICEF, 2015).

In Somalia, water and sugar mixed with water are widely given to infants, beginning in the first few months of life (Dewey, 2003). Women have one of the most dilute milks of all species, and therefore infants should be expected to feed very often, but frequency varies between individuals and even changes in the same individual at different times during lactation. Some babies are fussy and demanding, and seem to have a small stomach capacity. They want to feed every one to two hours throughout the day and night. Other babies have a larger capacity and are more peaceful; they demand to be fed only five times a day. The only constant feature among babies is that none seem to be very hungry for the first few days. They may want to feed only two, three or four times a day, but from the third day onwards this pattern changes. If a baby is given the opportunity to feed on demand, it may want to feed as many as 10-20 times a day (Villegas and Stuebe, 2013).

\section{Duration of breastfeeding}

A study done in Europe showed that the duration of breast-feeding was negatively correlated with increment in length and weight until 12 and 24 months (Haschke, 2000).During the newborn period, most breastfeeding sessions take 20 to 45 minutes. However, because newborn babies are often sleepy, this length of time may require patience and persistence.It is relevant to note that there are significant social pressures in the mother's life, such as returning to work, that influence breastfeeding duration, and certain barriers that are unique to specific vulnerable populations (Pelletier et al, 1994).

Dewey (2003) noted that perceptions and attitudes about breastfeeding could explain the observed differences in breastfeeding behavior among various socioeconomic groups of 
women, which is why educational strategies are recommended targeting these barriers and predictors of breastfeeding. Pain perception related to breastfeeding, loss of freedom, embarrassment with breastfeeding in public, perceived difficulty with breastfeeding, and perceived insufficient milk supply are the most prevalent reported reasons for breastfeeding discontinuation among women.

The duration of each feed does not matter, probably, even in the first few days. The mother should be encouraged to nurse for at least five minutes to enable the baby not only to get the "fore-milk", but to drink the "hind-milk" too. During the hours between feeds, milk of a low-fat content passively diffuses across the alveola gland cells and into the ducts. This milk, which collects in the lactiferous sinuses, is often called "fore-milk". It looks like skim milk, and mothers who notice that their milk is very watery can become concerned, thinking that they produce milk of low or poor quality.

The agreed and acceptable total duration of breastfeeding is 24 months, which is based on the Koranic verse 2:233 surah Al-Baqarah - "Mothers should breastfeed their children two full years, provided they want to complete the nursing".

\section{Termination of breastfeeding}

Breastfeeding on demand continued breastfeeding to two years, accompanied by appropriate complementary feeding, maintains good nutritional status and continues to help prevent diarrhoea (UNICEF, 2007).

\section{Complementary feeding}

From six months onwards, when breast milk alone is no longer sufficient to meet all nutritional requirements, infants enter a particularly vulnerable period of complementary feeding during which they make a gradual transition to eating family foods. The incidence of malnutrition rises sharply during the period from 6 to 18 months of age in most countries, and the deficits acquired at this age are difficult to compensate for later in childhood (UNDP, 2006).

According to WHO (2009) exclusive breastfeeding can be defined as a practice whereby the infants receive only breast milk without mixing it with water, other liquids, tea, herbal preparations or food in the first six months of life, with the exception of vitamins, mineral supplements or medicines.

Complementary food is the additional nutrient-rich food and drink that is recommended for children from six months of life. The transition from exclusive breastfeeding to complementary feeding (which includes continued breastfeeding) typically covers the period from 6 to 18-24 months of age. This is a very vulnerable period as it is the time when malnutrition starts in many children. Thus it is essential that infants receive appropriate, adequate and safe complementary foods to ensure the right transition from breastfeeding to the full use of family foods. Most nutritionists agree that children need solid food in addition to breast milk when they are age 4-6 months in order to reach their full growth potential (Mark, 2005).

Information concerning complementary feeding (CF) practice during infancy and early childhood is still scarce in Somalia, although it is obvious that mixed feeding (i.e. cow milk, formula or water) is started as early as from birth (Mark, 2005).

\section{Types of complementary foods}

A study done in Tanzania revealed that the most common type of weaning food was maize porridge (gruel) mixed with cow's milk (46\%) (Nyaruhucha et al, 2006). Other types include: 
baby rice cereals, puréed or well-mashed cooked vegetables, such as potato, sweet potato, butternut squash, parsnip, carrot, courgette, broccoli or cauliflower, fruit purée, such as ripe cooked apple, pear, mango or papaya or mashed fruit such as ripe avocado or banana (Godfrey and Lawrence, 2010).

\section{Early and late introduction of complementary foods}

Timing of the first introduction of solid food during infancy may have potential effects on lifelong health. It can be seen that very often solid foods are either given too early or too late (WHO/UNICEF, 1990). According to UNICEF (2012), the frequency and amounts of food that is given may be insufficient hence; hindering the normal growth of the child or their consistency or energy density may be incorrect in relation to the child's needs.

\section{Early weaning}

Weaning is the process by which a baby slowly gets used to eating family or adult foods and relies less and less on breast milk. The process varies from culture to culture and is often regulated by the child's individual needs. Healthy babies of weaning age are growing and developing very fast, so great care has to be taken to see that they are getting enough of the right kind of food (Engle, 2007).

Weaning can begin whenever a mother wishes, but she should be reminded of the recommendation that breast milk is the ideal food, and as long as her baby is gaining weight satisfactorily, supplementation is unnecessary. At about six months of age the baby's iron stores are depleted, and either iron-fortified cereal should be introduced, or else iron supplements should be started (Amal et al, 2007).

Ideally, mothers should slowly drop the frequency of breastfeeding and introduce a cup at this time. Cow's milk should not be given before the baby is nine to 10 months old because it is known to be allergenic to many infants. If a mother weans gradually, she should not experience any problems (Burke et al. 2015).

Some studies have shown that giving solid foods too early may lead to increased risk of chronic diseases such as islet autoimmunity (the pre-clinical condition leading to Type 1 diabetes), obesity, adult onset of celiac disease, and eczema. Nevertheless, it was affirmed there is no evidence of harm even within populations that begin weaning within a few days of birth (Wambui, 2005).

\section{Late Weaning}

Weaning onto solid foods is necessary as the needs of the rapidly growing infant can no longer be met by breast or formula milk alone. From about 6 months infants have decreased body stores of iron and vitamin D combined with increased needs for these and other nutrients. Weaning enables infants to learn new skills that are required for them to progress through key developmental stages for speech and self-feeding. It is an important opportunity to introduce a variety of tastes and textures that helps baby to learn to eat a varied and balanced diet and to avoid problems with faddy eating at later stages (Childinfo, 2009).

Appropriate weaning is an important factor in preventing many health and development problems in babies, children and throughout life including obesity, faltering growth and stunting, iron deficiency, specific nutrient deficiencies, dental caries and developmental delay. It is vital to help parents and carers make the most of this important opportunity to influence their child's future health and potential (Clemens, 2009). 
Weaning should not be delayed beyond 6 months as from this time breast or formula milk is no longer sufficient to meet all the nutritional needs of the growing baby (although breast milk or formula will still be the major source of nutrients for many months after the start of weaning.)

A study has shown that late weaning may cause deficiencies of zinc, protein, iron and vitamins $\mathrm{B}$ and $\mathrm{D}$ that leads to the suppression of growth and cause feeding problems. Iron deficiency anaemia and rickets are also found to be more prevalent among infants who are weaned after 6 months (Wambui, 2005).

\section{Frequency of feeding}

Breastfeeding is a complex physiological process, and full milk production is reliant upon adequate milk synthesis, secretion, ejection, and removal from the breast. During established breastfeeding, milk synthesis rates are largely under autocrine control, in that synthesis slows as breast fullness increases. Thus, ineffective milk removal will result in in-complete breast drainage and down-regulation of milk synthesis, which if prolonged may result in inadequate milk production (Amal et al, 2011).

Women are encouraged to attempt breastfeeding as soon as the infant begins to show signs of hunger. Early signs of hunger include awakening, searching for the breast (called rooting), or sucking on the hands, lips, or tongue. Most infants do not cry until they are very hungry; waiting to breastfeed until an infant cries is not recommended. In the first one to two weeks, most infants will breastfeed 8 to 12 times per day. Some infants will want to nurse frequently, as often as every 30 to 60 minutes, while others will have to be awakened and encouraged to nurse. A baby may be awakened by changing the diaper or tickling the feet. During the first week of life, most clinicians encourage parents to wake a sleeping infant to nurse if four hours have passed since the beginning of the previous feeding. Some babies will cluster feed, meaning that they feed very frequently for a number of feedings and then sleep for a longer period (Clemens, 2009).

Caring for an infant can be an exhausting experience. However, it may be comforting to know that breastfeeding is no more time consuming than formula feeding, which often requires additional time to purchase and prepare the formula and wash bottles and nipples. The length of time an infant needs to finish breastfeeding varies, especially in the first few weeks after delivery; some infants require as little as 5 minutes while others need 20 minutes or more. Most experts recommend that the infant be allowed to actively breastfeed for as long as desired; timing the feeding (ie, watching the clock) is not recommended. "Active" breastfeeding means that the infant is regularly suckling and swallowing (Burke et al, 2015).

It is not necessary to switch sides in the middle of a nursing session. Thorough emptying of one breast allows the baby to consume milk from deeper in the breast, which has a higher fat content than milk available at the start of a nursing session. Most infants signal that they are finished nursing by releasing the nipple and relaxing the facial muscles and hands. Infants younger than two to three months often fall asleep during nursing, even before they are finished. In this case, it is reasonable to try and awaken the child and encourage him/her to finish nursing. After finishing one breast, offer the other side with the understanding that the infant (especially an older infant) may not be interested.

The minimum feeding frequencies recommended, the number of times a child must be fed with complementary feed depends on his/age and whether the child is being breastfed or not. Guidelines for breastfed children are: at 6-8 month, meals of complementary food 2-3 times /day, with 1-2 snacks as desired; at 9-23 month, meals of complementary food 3-4 times/day, 
with 1-2 snacks as desired (PAHO/WHO, 2003). For non-breastfed infants and children below two years, meals should be given 4-5/day, with 1-2 snacks as desired (WHO, 2005).

\section{Bottle-feeding}

Bottle feeding is the practice of feeding an infant as a substitute for breast milk. Pediatricians generally advise exclusively breastfeeding (that is, breastfeeding with no supplementary formula) for all full-term, healthy infants for the first 6 months of life. However, many infants are bottle fed today, at least in part. For infants to achieve normal growth and maintain normal health, infant formulas must include proper amounts of water, carbohydrate, protein, fat, vitamins, and minerals but they can introduce baby into the body (Cernades, Nocada and Barrera, 2013).

A study conducted in Nairobi on infantile diarrhoea showed that diarrhoea persisted for 8-14 days among $17 \%$ of breastfed infants, $28 \%$ of bottle-fed infants, and $35 \%$ of infants fed by a combined method. Bottle-feeding is practiced by $2 \%$ and $3 \%$ of mothers of infants under four months in Eritrea and Zambia (ANON, 2003). Study conducted by UNUCEF in Somaliland in 2014 showed that $51 \%$ of the infants are Bottle-fed. This means that majority of the infants and children below 24 months were bottle-fed.

\section{Relationship between feeding practices and nutritional status}

Breast milk has a major impact on child health, growth and development. Infants should exclusively breastfeed (EBF) for six months, then, nutritionally adequate and safe complementary foods should be introduced (Lewis and Toby, 2006).

Study conducted in Nairobi-Kenya has shown that there is a significant association between delay in time of breastfeeding initiation after childbirth and stunting P $\leq .05$ (odds ratio 2), discontinuation of breastfeeding and underweight $\mathrm{P} \leq .05$ (odds ratio 4.5), as well as weaning less than six months and underweight $\mathrm{P} \leq .05$ (odds ratio 2.5). There was no significant association between breastfeeding practices and wasting. Children on bottle feeding and those who had discontinued breastfeeding were likely to be wasted (odds ratio 1.6) (Monique, Jeny and David, 2010).

Malnutrition is a major public health problem worldwide. It affects all age groups and populations, especially the poor and vulnerable ones. 1 of the 10.4 million children below 5 years of age who die of preventable causes in developing countries each year, over $50 \%$ die of malnutrition.2 Moreover, many infectious illnesses, particularly acute respiratory infection and diarrhea, are related to malnutrition. The World Health Organization reported that inappropriate feeding in children is responsible for one-third of the cases of malnutrition. This cross-sectional study aimed to determine the prevalence of malnutrition and identify the relationship between feeding practices and malnutrition in children below 5 years, in 7 remote and poor counties of China (Monique, Jeny and David, 2010).

The World Health Organization (WHO) estimated that inappropriate feeding of infants and young children was responsible for one-third of the cases of malnutrition worldwide. It has been recognized that inappropriate feeding practices include absence of exclusive breastfeeding in children below 6 months old, premature ablactation after 6 months, and giving complementary foods too late (Monique, Jeny and David, 2010). 


\section{Study Design}

\section{METHODOLOGY}

The study was conducted between August to December 2016 using community-based cross sectional study design.

\section{Study Population}

The study populations were children under two years and their mothers in Heliwa District.

\section{Study Area}

This study was carried out in Heliwa District, which lies in the northern part of Benadir region of Somalia. It has got geographical boundaries with Karan district in the east and south, Yaqshid district in the west and middle Shabelle region in the north. It has also a number of health facilities notably SOS Maternal and Child Health Clinic and its main market is Hilwa Market.

\section{Data Collection Technique and Tools}

Primary data was collected by the use of administered structured questionnaires which was made up of both open and close-ended questions. Besides, key informant discussions for experts of feeding practices were held and finally the nutritional status of the children was determined using anthropometric measurements.

\section{Sample size}

Sample size was calculated using Kish Leslie (1965) formula for cross sectional studies. Sampling units were children under two years and their mothers. A sample size of 403 was studied using the Epi info Stat calculator based on prevalence of 50 to ensure maximum sample size with 5\% error, 95\% confidence interval with 5\% nonresponse rate and a population size of children under two years 10323.

$$
\mathrm{n}=\left[\frac{Z^{2} P Q}{\delta^{2}}\right]
$$

n - Sample Size

$\mathbf{Z}$ - Parameter related to error risk, equal to 1.96 or 2 for error of $5 \%$

$\mathbf{P}=$ Expected prevalence of malnutrition of the population, expressed as a fraction of 1

d - Degree of accuracy, expressed as fraction of 1

$\mathbf{q}=1-\mathrm{P}$, expressed proportion of children not malnourished, expressed as a fraction of 1

$$
\begin{aligned}
& \text { If } \\
& \mathbf{P}=50 \% \\
& \mathbf{q}=50 \\
& \mathbf{Z}=1.96
\end{aligned}
$$

\section{By substitution}

$\mathrm{n}=\left[\frac{Z^{2} P Q}{\delta^{2}}\right] \quad 1.96^{\wedge} 20.5^{*} 0.5 / 0.5^{\wedge 2} \quad=384$

Nonresponse compensation account was 5\% (=19)

Therefore, Sample size of $(384+19)=403$ 


\section{Sampling Procedure}

Heliwa district consists of five administrative sections namely Gubadley, Waxaracadde, Ceelcirfid, Barwaaqo and Suuqaxoolaha. To obtain a representative sample, all sections of the district were included in the study. Probability proportion to size sampling was used to select the number of households from each section. Thus the section with a bigger number of households had more participants in the study. A systematic random sampling was then used to select the households to participate in the study. To determine the starting point (household) random selection was made. At household level one child aged 2 years were recruited to participate in the study regardless of the number of children (less than 2 years) in that household, in case the household had more than one child aged less than 2 years, simple random sampling was performed to select one child to participate in the study. The caretakers were interviewed to obtain information about demographic factors, dietary feeding factors and health factors of their children. Children who were reported to be sick by their mothers were excluded.

Table 4.1: Sections, total households and sampled households

\begin{tabular}{lcc}
\hline Section & Total households & Sampled households \\
\hline Ceelcirfiid & 4941 & 112 \\
Barwaaqo & 5084 & 115 \\
Waxaracadde & 1852 & 42 \\
Suuqaxoolaha & 1342 & 31 \\
Gubadley & 4537 & 103 \\
Total households & 17756 & 403 \\
\hline
\end{tabular}

\section{Inclusion and Exclusion Criteria \\ Inclusion Criteria}

Children who aged less than 2 years at the time of study and their mothers or caretakers were included in the study. The child who had no deformity that could interfere with anthropometry assessment and the caretaker had to be present and in good mental health to give consent for inclusion were included.

\section{Exclusion Criteria}

Children with chronic illnesses, physical impairment or those whose parents were unwilling to participate were excluded from the study.

\section{Study variables}

Variables comprised of dependent and independent variables

Dependent variable: Nutritional status

Independent variables: initiation of breastfeeding, exclusive breastfeeding, breastfeeding on demand, time of weaning, early introduction of complementary feeds, frequency of feeding, types of complementary foods, educational level, age of mother, marital status, educational level, occupation of parents, and parity.

\section{Quality Assurance}

\section{Training of research assistants}

A third year nursing students who fluently speak both English and Somali languages were selected as research assistants and then trained for two days about the study objectives, interviewing techniques, anthropometric procedures, data collection tools, ethical issues, responsibilities of data collectors and quality control. 


\section{Pre-testing}

Data collection technique and tools were tested before the actual data collection at one section of Heliwa District that has similar profile as other sections in terms of socioeconomic factors. Corrections were made where necessary to validate the tools.

\section{Missing data}

The returned and completed tools have been cross-checked by the researcher to ascertain their completeness. Questionnaires with missing data were re-administered to the respondents for correction.

\section{Data Handling}

Two research assistants were identified and trained to standardize data collection procedures. Soft copies of data were coded and hard copies locked in a locker in the office of the principal researcher. Research team had access to data only when permission was granted by the principal researcher. Data entry and cleaning have been done on a computer excel, Epi-data \& ENA Smart.

\section{Data Analysis}

The Data were analysed based on the stated objectives using ENA Smart, STATA-12 and excel soft wares. Where appropriate, results were presented as frequencies, tables, histograms and pie charts.

The sex specific 1978 CDC/WHO normalized version of the 1977 NCHS reference curves for height-for-age, weight-for-age, and weight-for-height incorporated in Epi info software were used to transform the anthropometric data obtained into weight-for-age (W/A), length-for-age (H/A) and weight- for- length $(\mathrm{W} / \mathrm{H})$.

Some statistical assessments were made by comparing means, standard deviations and 95\% confidence intervals (CI 95\%) where appropriate. The chi-square analysis and Prevalence Odds Ratios were also used to determine the relationships and strength between variables. Level of significance was set at $\mathrm{P}<0.05$. The confounding factor of infection and disease were dealt with by excluding the sick children. All variables with $\mathrm{p}$ value less or equal to 0.2 at bivariate level, those which were significant to the previous studies and whose which were significant in this study were entered into logistic regression for further analysis to adjust confounders.

\section{Ethical Considerations}

Ethical clearance for this research was obtained from the District Health Administration, District Research Committee and individuals who were to be interviewed. Mothers, caretakers, families and all participants were educated on the relevance of the study and included in the research based on their consent to participate.

\section{Informed consent}

The respondents were requested to participate in the research by answering the questionnaire through the research assistants and allowing them their child to be anthropometrically measured. Their participation was voluntary and they had freedom to withdraw at any time if they might feel so and there was no victimization for any withdrawal. 


\section{Privacy and Confidentiality}

All information provided to the interviewers was strictly kept confidential and records securely stored in a locker. All information that respondents gave were handled with security and confidentiality.

\section{Anonymity}

The participant's name and identity were kept anonymous. Only their responses and findings presented in the study.

\section{RESULTS}

\section{Socio-demographic characteristics of children and their caretakers}

The mean age of the respondents (care takers) was 25.6 years with a standard deviation of 6.6 while almost half of them (48.14\%) were within the range of 15-24 years. Majority of the respondents $(95.8 \%)$ were married and $2.7 \%$ were divorced. The findings also revealed that $60.3 \%$ of respondents had no formal education while $26 \%$ had primary education, while very few $10.4 \%$ and $3.2 \%$ had secondary and tertiary education respectively. Majority 190 (47.2\%) of children were aged between $0-4$ months with a small number $23(5.7 \%)$ aged between 20 24 months. Furthermore, the study has shown that the majority of the children (55.6\%) were males while the remaining $44.4 \%$ were females.

The study found out that most 310 (76.9\%) of the mothers didn't know the birth weight of their children. Among mothers who knew the birth weight $14(3.5 \%)$ responded that their infants were born with low birth weight. Concerning parity, 327 (61.8\%) of the respondents have had 1 to 5 births while, 154 (38.3\%) have had more than 5 births. This is in line with family size in which majority $249(61.8 \%)$ of the families consist of 1-5 individuals, 134 (33.3\%) of the respondents family consists of 6-10 individuals and few $2(0.5 \%)$ of them were more than 16 members with mean family size of 5.7 .

The study findings show that the majority 164 (40.7\%) of husbands were self-employed, while $142(35.5 \%)$ were private employers and unfortunately a few of them $39(9.7 \%)$ were unemployed. 


\begin{tabular}{llll}
\multicolumn{2}{c}{ Table 5.1: Sociodemographic characteristics of caretakers and their children } \\
\hline Variable & Frequency (\%) & Variable & Frequency (\%) \\
\hline Mother's Age & & & \\
$15-24$ & $194(48.1)$ & Mother's Edu level & \\
$25-34$ & $174(43.2)$ & Primary Education & $243(60.3)$ \\
$35-44$ & $34(8.4)$ & Secondary Education & $105(26.0)$ \\
45 and above & $1(0.3)$ & Tertiary Education & $42(10.4)$ \\
Child's Sex & & Marital status of caretaker & $13(3.2)$ \\
Male & $224(55.6)$ & Single & \\
Female & $179(44.4)$ & Married & $3(0.74)$ \\
Parity & & Divorced & $386(95.8)$ \\
$1-5$ & $327(81.1)$ & Widowed & $11(2.7)$ \\
$6-10$ & $68(16.9)$ & Husband Occupation & $3(0.7)$ \\
$11-15$ & $5(1.2)$ & Employee & \\
16 and above & $3(0.7)$ & Government Worker & $142(35.2)$ \\
Family size & & Self-employed & $58(14.4)$ \\
$1-5$ & $249(61.8)$ & Unemployed & $164(40.7)$ \\
$6-10$ & $134(33.3)$ & Child age brackets & $39(9.7)$ \\
$11-15$ & $18(4.5)$ & $0-4$ & $190(47.2)$ \\
$16 \&$ above & $2(0.5)$ & $5-9$ & $68(16.9)$ \\
Child's birth weight & & $10-14$ & $88(21.8)$ \\
$1000-2400 g$ & $14(3.5)$ & $15-19$ & $34(8.4)$ \\
$2500-4000 g$ & $66(16.4)$ & $20-24$ & $23(5.7)$ \\
$>4000 g$ & $13(3.2)$ & Child infection (last 2 weeks) & \\
I don't know & $310(76.9)$ & Yes & $63(15.6)$ \\
& & No & $340(84.4)$ \\
\hline & & & \\
\hline & & &
\end{tabular}

\section{Nutritional status of the children under two years}

The prevalence of moderate and severe underweight was $17.6 \%$ and $13.1 \%$, respectively. Moderate and severe stunting were $14.9 \%$ and $12.6 \%$, respectively, while $12.4 \%$ were moderately wasted and $16.1 \%$ were severely wasted as shown in table 5.2 .

Table: 5.2: Distribution of child's age (in months), sex and nutritional status

\begin{tabular}{|l|l|c|c|c|c|c|c|}
\hline Characteristics & No. & $\begin{array}{c}\text { Moderately } \\
\text { Underweight }\end{array}$ & $\begin{array}{c}\text { Severely } \\
\text { Underweight }\end{array}$ & $\begin{array}{c}\text { Moderately } \\
\text { Stunted }\end{array}$ & $\begin{array}{c}\text { Severely } \\
\text { Stunted }\end{array}$ & $\begin{array}{c}\text { Moderately } \\
\text { Wasted }\end{array}$ & $\begin{array}{c}\text { Severely } \\
\text { Wasted }\end{array}$ \\
\hline $\begin{array}{l}\text { Sex } \\
\text { Male }\end{array}$ & 224 & $39(17.4)$ & $34(15.2)$ & $36(16.1)$ & $21(9.4)$ & $26(11.6)$ & $45(20)$ \\
\hline Female & 179 & $32(17.9)$ & $19(10.6)$ & $24(13.4)$ & $30(16.8)$ & $24(13.4)$ & $20(11.0)$ \\
Total & $\mathbf{4 0 3}$ & $71(17.6)$ & $53(13.1)$ & $60(14.9)$ & $51(12.6)$ & $50(12.4)$ & $65(16.1)$ \\
Age & & & & & & \\
$0-4$ & 190 & $34(17.9)$ & $26(13.6)$ & $27(14.2)$ & $23(12.1)$ & $24(12.6)$ & $36(18.9)$ \\
$5-9$ & 68 & $10(14.7)$ & $16(23.5)$ & $6(8.8)$ & $15(22.1)$ & $5(7.4)$ & $14(20.6)$ \\
$10-14$ & 88 & $19(21.6)$ & $8(9.1)$ & $8(9.1)$ & $15(17.0)$ & $13(7.4)$ & $12(13.6)$ \\
$15-19$ & 34 & $5(14.7)$ & $2(5.9)$ & $4(11.8)$ & $4(11.8)$ & $6(17.6)$ & $2(5.9)$ \\
$20-24$ & 22 & $3(13.6)$ & $1(4.5)$ & $6(27.3)$ & $2(9.1)$ & $1(4.5)$ & $2(9.1)$ \\
\hline
\end{tabular}

The highest prevalence of malnutrition was among the age group 5-9 months of which 38.2\% were underweight, $32.3 \%$ stunted and $28 \%$ wasted in which $97 \%$ fell below minus 2 and minus 3 standard deviations from the median.

The prevalence of underweight among the males was $32.6 \%$ while that of the females $28.5 \%$. Again, $25.5 \%$ of males were stunted while $30.2 \%$ females were stunted. However, $31.6 \%$ males were wasted while $24.4 \%$ females were wasted. 


\section{Breastfeeding practices of the mothers}

The findings show that the majority 346 (85.9\%) of the mothers have ever breastfed their children if they were not at the time of the data collection. Again the same number 346 (85.86) of mothers said that they gave the colostrum to their infants.

Majority 287 (75.2\%) of the mothers initiated breastfeeding to their children on the first day after birth while $88(23.5 \%)$ among mothers who initiated breastfeeding on the first day, their majority 232 (67.1\%) started breastfeeding 2 hours after delivery.

Concerning exclusive breastfeeding majority 265 (65.8\%) of the mothers don't exclusively breastfeed their children while 138 (34.2\%) breastfeed exclusively.

The study revealed that the majority $300(74.4 \%)$ who breastfeed/breastfed give breastmilk on demand with a frequency of seven times and more mostly $207(60 \%)$ at day time and 1-3 times at night 189 (54.5\%).

It was also found out that $63.3 \%$ of the mothers terminate breastfeeding before 20 months while $36.7 \%$ stop breastfeeding between $20-24$ months.

Table 5.3: Distribution of breast feeding practices

\begin{tabular}{llll}
\hline Variable & Frequency (\%) & Variable & Frequency (\%) \\
\hline Child ever being breastfed & & Breast feeding initiation & $287(75.2)$ \\
Yes & $346(85.9)$ & Day one & $78(20.8)$ \\
No & $57(14.1)$ & Day two & $7(1.86)$ \\
Colostrum & & Day three & $3(0.8)$ \\
Yes & $346(85.9)$ & Beyond day three & $7(5.8)$ \\
No & $57(14.1)$ & Termination of breastfeeding & $14(11.7)$ \\
Exclusive breast feeding & $138(34.2)$ & $1-4$ Months & $23(19.2)$ \\
Yes & $265(65.8)$ & $5-9$ Months & $32(26.7)$ \\
No & & $10-14$ Months & $44(36.7)$ \\
Still breastfeeding & $226(65)$ & $15-19$ Months & \\
Yes & $120(35)$ & $20-24$ Months & $300(74.4)$ \\
No & & Breast feeding on demand & $103(25.6)$ \\
Frequency of breastfeeding & at & Yes & No \\
$1-3$ times & & Frequency of breastfeeding at & $102(29.5)$ \\
$4-6$ times & $56(16)$ & night-time & $189(54.5)$ \\
7 and above & $83(24)$ & None & $55(16)$
\end{tabular}

\section{Complementary feeding patterns of the mothers}

Most $85.9 \%$ of respondents started giving water to their children when they were less than 6 months old. Few (14.1\%) of the children less than 6 months had not been given water. However, $46.8 \%$ of respondents reported giving their children water on the very first day of life, because they said that there was no milk in their breast. 
Table 5.4: Distribution of Complementary feeding practices

\begin{tabular}{|c|c|c|c|}
\hline Variable & Frequency (\%) & Variable & Frequency (\%) \\
\hline Initiation of complementary & & Local CF given & \\
\hline feeding & & Crashed cooked potatoes & $46(17)$ \\
\hline Yes & $192(47.67)$ & Biscuits & $35(13.5)$ \\
\hline No & $211(52.36)$ & Mashed pancake & $93(35)$ \\
\hline Introduction of water & & Mashed fruits/vegetables & $18(7.0)$ \\
\hline Before 6 months & $346(85.9)$ & Water & $73(27.5)$ \\
\hline After 6 months & $57(14.1)$ & Bottle feeding & \\
\hline Snack meals & & Yes & $229(56.8)$ \\
\hline Yes & $84(20.84)$ & No & $174(43.2)$ \\
\hline No & 319 (79.16) & & \\
\hline \multicolumn{4}{|l|}{ Infant formula } \\
\hline Yes & $242(60)$ & & \\
\hline No & $161(40)$ & & \\
\hline
\end{tabular}

\section{Local complementary foods commonly used}

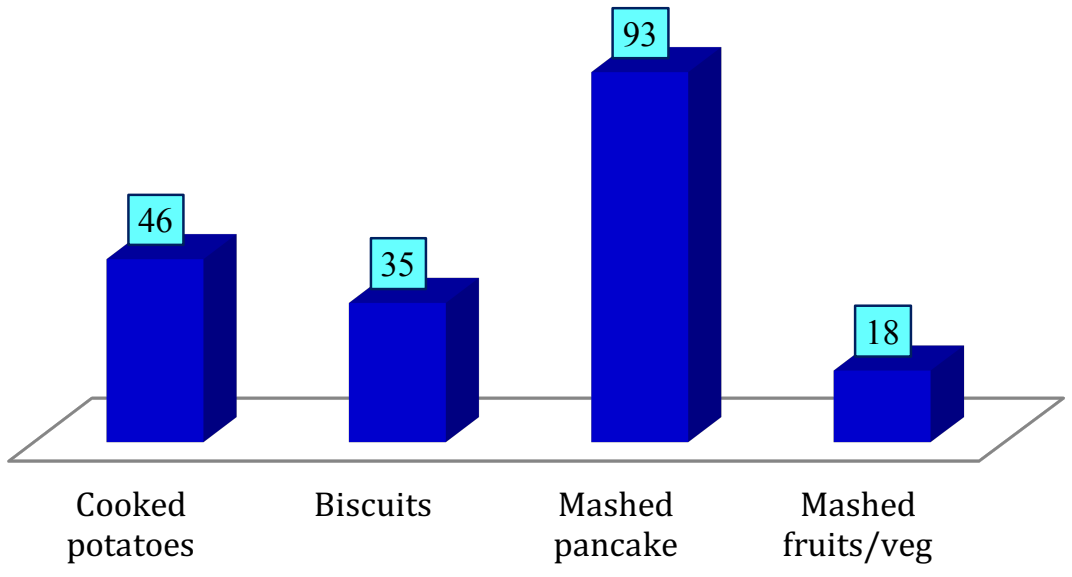

Fig 5.3: Distribution of the different types of complementary feeds given to the children

The figure above shows that the majority 93 (35\%) of the mothers wean their children with mashed pancake while a few $18(7 \%)$ wean theirs with mashed fruits and vegetables.

Relationship between feeding practices and nutritional status of children under 2 years Association between socio-demographic factors with underweight, stunting and wasting The results in table 5.6 show the relationship between sex of the child, age of the child, mother's education and father's occupation. It was found that sex of the child, mother's education and father's occupation was significant. Female children were 1.4 times more likely to be underweight compared to their male counterparts (OR 1.40, 95\%CI 1.15-1.90), but not stunting and wasting. There was no significant relationship/association between age of the child and underweight, stunting and wasting as shown in table 5.6. The research also revealed that children whose mothers have had tertiary education (College or University) were less likely to be underweight, stunting and wasting compared to others who have not had tertiary education [(OR 0.53, 95\%CI 0.38-0.74), (OR 0.62, 95\%CI 0.19-0.97), and (OR 0.55, 95\%CI 0.350.88)] respectively. Moreover, children whose fathers were self-employed were less likely to develop wasting than private employees (OR 0.75, 95\%CI 0.42-0.85) while children whose fathers were unemployed were 2 times more likely to develop wasting than employed. Age variable was not significantly associated with malnutrition in this study. 
Table 5.6 Socio- demographic factors associated with wasting, stunting and underweight

\begin{tabular}{|c|c|c|c|c|c|c|c|c|c|c|}
\hline & & & Unde & weight & & & Stunting & & & Wasting \\
\hline Variables & $\mathbf{N}$ & $n(\%)$ & OR & 95\%(CI) & $n(\%)$ & OR & 95\%(CI) & n (\%) & OR & $95 \%(C I)$ \\
\hline Sex & & & & & & & & & & \\
\hline Male & 224 & $73(32.6)$ & 1.0 & & $73(32.6)$ & 1.0 & & $71(31.6)$ & 1.0 & \\
\hline Female & 179 & $51(28.5)$ & 1.40 & 1.15 & $54(30.2)$ & 0.79 & $0.51-1.23$ & $54(30.1)$ & 1.45 & $0.93-2.26$ \\
\hline Age & & & & $1.90^{*}$ & & & & & & \\
\hline $0-4$ & 190 & $60(31.6)$ & 1.0 & & $50(26.3)$ & 1.0 & & $60(31.6)$ & 1.0 & \\
\hline $5-9$ & 68 & $26(38.2)$ & 0.75 & & $21(30.9)$ & 0.79 & $0.43-1.47$ & $19(27.9)$ & 1.19 & $0.64-2.19$ \\
\hline $10-14$ & 88 & $27(30.7)$ & 1.04 & $0.42-1.33$ & $23(26.1)$ & 1.00 & $0.57-1.79$ & $25(31.8)$ & 1.16 & $0.67-2.03$ \\
\hline $15-19$ & 34 & $7(20.6)$ & 1.78 & $0.60-1.80$ & $8(23.5)$ & 1.16 & $0.49-2.74$ & $8(23.5)$ & 1.50 & $0.63-3.52$ \\
\hline $20-24$ & 22 & $4(18.2)$ & 1.66 & $0.73-4.34$ & $8(36.4)$ & 0.55 & $0.23-1.37$ & $3(13.6)$ & 2.19 & $0.71-6.78$ \\
\hline Mother's & & & & $0.59-4.71$ & & & & & & \\
\hline Education Level & & & & & & & & & & \\
\hline No formal edu & 242 & $72(29.7)$ & 1.0 & & $67(27.7)$ & 1.0 & & $69(28.5)$ & 1.0 & \\
\hline Primary & 105 & $37(35.2)$ & 0.80 & & $28(26.7)$ & 1.07 & $0.63-1.79$ & $29(27.6)$ & 1.06 & $0.63-1.76$ \\
\hline Secondary & 45 & $12(26.6)$ & 0.75 & $0.48-1.28$ & $10(22.2)$ & 1.24 & $0.57-2.67$ & $14(31.1)$ & 0.81 & $0.40-1.63$ \\
\hline Tertiary & 13 & $3(23.0)$ & 0.53 & $0.24-2.21$ & $5(38.4)$ & 0.62 & 0.19- & $3(23.0)$ & 0.55 & $0.35-$ \\
\hline Father's Occu & & & & $0.38-$ & & & $0.97 *$ & & & $0.88^{*}$ \\
\hline Priv. Employee & 140 & $51(36.4)$ & 1.0 & $0.74 *$ & $38(27.1)$ & 1.0 & & $35(25.0)$ & 1.0 & \\
\hline Gov. Employee & 58 & $13(22.4)$ & 1.98 & & $15(25.8)$ & 1.06 & & $15(25.8)$ & 0.95 & \\
\hline Self-employed & 164 & $55(33.5)$ & 1.13 & & $53(32.3)$ & 0.78 & $0.53-2.14$ & $53(32.3)$ & 0.75 & $0.47-1.93$ \\
\hline Unemployed & 40 & $5(12.5)$ & 3.15 & $0.97-4.05$ & $27(67.5)$ & 2.53 & $0.47-1.28$ & $10(25.0)$ & 2.0 & $0.42-0.85$ \\
\hline & & & & $\begin{array}{l}0.71-1.82 \\
1.21-8.18\end{array}$ & & & $0.91-7.04$ & & & $\begin{array}{l}1.42- \\
2.88^{*}\end{array}$ \\
\hline
\end{tabular}

*= significant where $\mathrm{P}$-value $<0.05, \mathrm{OR}=$ Odds ratio, $\mathrm{CI}=$ Confidence interval

\section{Breast feeding practices associated with underweight, stunting and wasting}

The results in table 5.6 show the association between dietary feeding practices, underweight, stunting and wasting. Initiation of breastfeeding, exclusive breastfeeding, timely complementary feeding and bottle feeding were found to be associated with malnutrition. Concerning early initiation of breastfeeding, children who were initiated breastfeeding beyond day three were more likely to be wasted compared to those started breastfeeding on the first day (OR 1.78, 95CI 1.02-2.54). Furthermore, children who were not exclusively breastfed were more likely to be underweight as well as wasted [(OR 2.12, 95\%CI 1.43-2.58) and (OR 1.9, 95\%1.51-3.32)] respectively.

Other factors such as; ever breastfed and still breastfeeding were not significantly associated with malnutrition in this study.

\section{Complementary feeding practices associated with underweight, stunting and wasting}

The current study found out that complementary feeding initiation time and bottle feeding were associated significantly with malnutrition.Regarding timely complementary feeding, children who were introduced complementary foods late in time were more likely to be underweight and wasted compared to those introduced complementary foods timely [(OR $1.59,95 \%$ CI 1.22-2.91) and (OR 1.4, 95\%CI 1.09-2.43] respectively. Again it was also found that children who never used bottle feeding were less likely to be stunted than bottle users (OR 0.83, 95\%CI 0.39-0.96). 
Table 5.7 Association between feeding practices and underweight, stunting and wasting

\begin{tabular}{|c|c|c|c|c|c|c|c|c|c|c|}
\hline \multicolumn{3}{|l|}{ Variable } & \multicolumn{4}{|c|}{ Underweight } & \multicolumn{3}{|l|}{ Stunting } & \multirow{2}{*}{$\begin{array}{l}\text { Wasting } \\
95 \%(C I)\end{array}$} \\
\hline & $\mathbf{N}$ & $n(\%)$ & OR & $95 \%(C I)$ & $n(\%)$ & OR & 95\%(CI) & $n(\%)$ & OR & \\
\hline Ever breastfed & & & 10 & & & & & & & \\
\hline $\begin{array}{l}\text { Yes } \\
\text { No }\end{array}$ & $\begin{array}{c}346 \\
57\end{array}$ & $\begin{array}{l}45(13.0) \\
21(36.8)\end{array}$ & $\begin{array}{l}1.0 \\
1.8\end{array}$ & $0.45-2.45$ & $\begin{array}{l}23(6.6) \\
20(35.1)\end{array}$ & $\begin{array}{l}1.0 \\
0.72\end{array}$ & $0.39-1.32$ & $\begin{array}{l}22(6.35) \\
31(54.4)\end{array}$ & $\begin{array}{l}1.0 \\
2.5\end{array}$ & $0.39-1.32$ \\
\hline Initiation of BF & & & & & & & & & & \\
\hline First day & 272 & $43(15.8)$ & 1.0 & & $34(12.5)$ & 1.0 & & $36(13.2)$ & 1.0 & \\
\hline Second day & 78 & $24(30.7)$ & 1.24 & $0.86-1.81$ & $23(29.5)$ & 1.12 & $0.48-1.56$ & $24(30.7)$ & 1.65 & $0.43-1.96$ \\
\hline Third day & 5 & $2(40.0)$ & 1.55 & $0.31-5.88$ & $2(40.0)$ & 1.15 & $0.72-1.66$ & $1(20.0)$ & 1.73 & $0.94-2.33$ \\
\hline Beyond 3 day & 3 & $1(33.3)$ & 2.31 & $0.79-9.02$ & $1(33.3)$ & 1.19 & $0.52-1.78$ & $2(66.7)$ & 1.78 & $1.02-2.54 *$ \\
\hline Still breastfeeding & & & & & & & & & & \\
\hline Yes & 300 & $95(31.6)$ & 1.0 & & $59(20.0)$ & 1.0 & & $62(20.6)$ & 1.0 & \\
\hline No & 103 & $29(28.2)$ & 1.09 & $0.34-1.54$ & $32(31.1)$ & 1.34 & $0.47-1.65$ & $37(35.9)$ & 1.72 & $0.83-2.41$ \\
\hline BF on demand & & & & & & & & & & \\
\hline Yes & 167 & $36(21.6)$ & 1.0 & & $39(23.6)$ & 1.0 & & $22(13.2)$ & 1.0 & \\
\hline No & 236 & $84(35.6)$ & 1.25 & $0.43-2.76$ & $88(37.3)$ & 2.54 & $1.65-3.64^{*}$ & $64(27.1)$ & 3.31 & $0.69-6.35$ \\
\hline Exclusive BF & & & & & & & & & & \\
\hline Yes & 138 & $38(27.5)$ & 1.0 & & $27(19.6)$ & 1.0 & & $23(16.7)$ & 1.0 & \\
\hline No & 265 & $86(32.5)$ & 2.12 & $1.43-2.58^{*}$ & $78(29.4)$ & 1.78 & $0.47-2.92$ & $58(21.8)$ & 1.9 & 1.51-3.32 \\
\hline Timely CF & & & & & & & & & & \\
\hline Timely & 84 & $10(11.9)$ & 1.0 & & $6(7.1)$ & 1.0 & & $3(3.57)$ & 1.0 & \\
\hline Early & 49 & $9(18.4)$ & 1.12 & $0.27-4.52$ & $7(14.3)$ & 0.64 & $0.20-3.71$ & $5(10.20)$ & 0.95 & $0.43-2.92$ \\
\hline Late & 59 & $15(25.4)$ & 1.59 & $1.22-2.91^{*}$ & $9(15.3)$ & 1.23 & $0.45-3.67$ & $6(10.16)$ & 1.40 & $1.09-2.43^{*}$ \\
\hline Bottle feeding & & & & & & & & & & \\
\hline Yes & 229 & $86(37.6)$ & 1.0 & & $49(21.4)$ & 1.0 & & $26(11.4)$ & 1.0 & \\
\hline No & 174 & $35(20.1)$ & 0.71 & $0.21-1.82$ & $23(13.2)$ & 0.83 & $0.39-0.96^{*}$ & $10(5.7)$ & 1.76 & $0.34-5.82$ \\
\hline
\end{tabular}

$*$ = significant where $\mathrm{P}$-value $<0.05,0 \mathrm{R}=0 \mathrm{dd}$ s ratio, $\mathrm{CI}=$ Confidence interval

\section{Socio-demographic information}

\section{DISCUSSION}

The research brought to light that as many as $60.3 \%$ of respondents had no formal education. The highest educational attainment was a tertiary level and non-formal education was the lowest level. Only $10.4 \%$ and $3.2 \%$ of the respondents attained secondary and tertiary education respectively which is almost similar to a study done in Eritrea (ANON, 2003) and Chana (Mahgoub, 2012). However, maternal education has an inverse relationship with wasting. As the level of maternal education increases, the level of wasting also decreases. This is confirmed by a study done in Eritrea (ANON, 2003). Moreover, in this present study there was a relationship between maternal educational level and underweight, stunting and wasting. Children whose mothers have attained tertiary level of education are less likely to be underweight, stunting and wasting [(OR 0.53, 95\%CI 0.38-0.74), (OR 0.62, 95\%CI 1.19-0.97) and (OR 0.55, 95\%CI 0.35-0.88) respectively.

It was found that sex of the child, mother's education and father's occupation were significant. Female children were 1.4 times more likely to be underweight compared to their male counterparts (OR 1.40, 95\%CI 1.15-1.90), but not stunting and wasting. This might be due to Somali culture of son preference in which son is nursed/fed different from daughters. It may also be shying behavior and weakness of the girls in terms of striving for getting enough share.

There were no significant relationship/association between age of the child and underweight, stunting and wasting as shown in table 6 . The research also revealed that children whose mothers have had tertiary education (College or University) were less likely to be underweight, stunting and wasting compared to others who have not had tertiary education [(OR 0.53, 95\%CI 0.38-0.74), (OR 0.62, 95\%CI 0.19-0.97), and (OR 0.55, 95\%CI 0.35-0.88) respectively. Moreover, children whose fathers were self-employed were less likely to develop wasting than private employees (OR $0.75,95 \%$ CI $0.42-0.85$ ) while children whose fathers were unemployed were 2 times more likely to develop wasting than employed (OR 2, 95\% CI 1.42-2.88). 


\section{Nutritional status of the children under two years}

Knowing the prevalence rates of underweight, wasting, and stunting is important for determining the overall health of the community and for monitoring achievements toward mid-decade goals for nutrition and child health set by international organizations (Bloss et al, 2014; WHO, 2015). Based on the data analyzed, it was revealed that $30.7 \%$ of the children were underweight, $27.5 \%$ were stunted and $28.5 \%$ were wasted.

Underweight or weight for age prevalence is usually the proportion of less than five falling below minus 2 standard deviations (this is termed as moderate underweight) and 3 standard deviations (severe underweight) from the median weight-for-age of the WHO/NCHS (UNICEF, 2008). Underweight is reversible and reflect either acute or chronic malnutrition. This study revealed that $30.7 \%$ of children under two are underweight. This is higher compared to the findings of the studies done in the neighbouring countries such as Nyanza province of Kenya which showed a prevalence of $18.1 \%$ for underweight (Ergin et al., 2015).

The overall finding revealed that $32.6 \%$ of males and $28.5 \%$ of females were underweight even though females were more likely to be stunted than males (OR 1.4, 95\%CI 1.15-1.90). However, the prevalence of underweight was higher among the boys than the girls. This is similar to the underweight prevalence in Ghana reported by UNICEF in 2008 as $18.3 \%$ and $17.1 \%$ for boys and girls respectively.

Stunting (low H/A) is a public health problem worldwide. It is a measure of cumulative deficient growth and a feature of a complex syndrome including developmental delay, impaired immune function, reduced cognitive development, metabolic disturbance leading to accumulation of body fat, loss of lean mass, and risk of hypertension (Branca, 2002; Martins, 2004). This study revealed that $14.9 \%$ and $12.6 \%$ of the children under two are moderate and severe stunting, respectively. However, $27.5 \%$ prevalence of stunting revealed in the findings is lower compared to $50 \%$ prevalence in Malawi (UNICEF, 2008) and $38.7 \%$ in Botswana (Mahgoub et. al, 2006) though these studies used children under 5 years of age.

Wasting, or low weight for height or acute malnutrition is a strong predictor of mortality among children under five. It is usually the result of acute significant food shortage and/or disease (UNICEF, 2007). The study revealed that $28.5 \%$ of the children under two are wasted however in UNICEF's 2007 report, it is stated that countries with $10 \%$ or more wasted underfives require urgent response. Since $28.5 \%$ is much far from $10 \%$ there is the need for an intervention. This finding is higher as compared to the $7.1 \%$ obtained from a survey done in Mbeere south district in Kenya and 10.7\% in Haramaya district, Ethiopia (Ijarotimi, 2012).

\section{Breastfeeding practices}

Breastfeeding is the normal way of providing young infants with the nutrients they need for healthy growth and development. Virtually all mothers can breastfeed, provided they have accurate information, and the support of their family, the health care system and society at large.

However, this study revealed that $85.9 \%$ of the children have ever been breastfed and $74.4 \%$ were breastfeeding on demand which is dissimilar to the finding of a study conducted in Mali which revealed that $100 \%$ of the children have ever been breastfed and breastfeeding on demand took place throughout the interview period (ANON, 2013). Even though underweight, stunting and wasting were not significantly associated with ever breastfed and breastfeeding on demand. 
A report (UNICEF, 2008) suggests that Breastfeeding on demand should be continued till the child is at least two years and must be accompanied by appropriate complementary feeding in order to maintain good nutritional status and help prevent diarrhoea.

On the other hand study has shown that exclusive breastfeeding was significantly associated with malnutrition. Children who were not exclusively breastfed were more likely to be underweight and wasted than those breastfed exclusively [(OR 2.12, 95\%CI 1.43-2.58) and (OR $1.9,95 \%$ CI 1.51-3.32] respectively but not stunting.

\section{Complementary feeding practices}

Most $85.9 \%$ of respondents started giving water to their children when they were less than 6 months old. Few (14.1\%) of the children less than 6 months had not been given water. However, $46.8 \%$ of respondents reported giving their children water on the very first day of life, because they said that there was no milk in their breast.

The study also showed that $20 \%$ of the children below 6 months were receiving semi-solid foods as at the time of data collection while $47 \%$ of children beyond 6 months were neither receiving semi-solid nor solid foods.

Furthermore, children who were introduced complementary foods late after six months were more likely to develop underweight and wasting [(OR 1.59 95\%CI 1.22-2.92) and (OR 1.40 95\%CI 1.09-2.43)] respectively.

Bottle feeding which is the process of feeding a baby with a bottle as opposed to nursing the infant. Bottle feeding is an important variable which has shown a significant association with malnutrition. Current study showed that majority (56.8\%) of the mothers who give infant formula use bottle feeding to feed their infants. Again the study has also revealed that children who were not bottle fed were less likely to become stunted compared to those who were not bottle fed (OR 0.83, 95\%CI 0.39-0.96).

Furthermore, study conducted in North Eastern Province of Kenya revealed that there was significant relationship between the children who were still receiving bottle feeding at the time of the data collection and underweight. These children were 1.4 times at increased risk of underweight. Besides, there was significant relationship between the children who were still receiving bottle feeding at the time of the data collection and stunting and wasting. But surprisingly these children were rather protected from stunting by 0.7 times $(\mathrm{P}=0.001 ; 0 \mathrm{R}=$ $0.7 ; \mathrm{CI}=0.371 .5)$ and wasting $(\mathrm{P}=0.001 ; \mathrm{OR}=0.8 ; \mathrm{CI}=0.27-2.64)$ by 0.8 times.

\section{CONCLUSION}

In conclusion, it was revealed that $30.7 \%$ of the children were underweight, $27.5 \%$ were stunted and $28.5 \%$ were wasted. Besides, the proportions of underweight $(56.7 \%)$, stunting $(59.7 \%)$ and wasting (68.2\%) were high in the children aged 13-23 months.

However, this study revealed that $85.9 \%$ of the children have ever been breastfed and $74.4 \%$ were breastfeeding on demand. Majority 287 (75.2\%) of the mothers initiated breastfeeding to their children on the first day after birth while few of them $10(2.66 \%)$ initiated three days and beyond after delivery. Among mothers who initiated breastfeeding on the first day, majority $232(67.1 \%)$ of them started breastfeeding 2 hours after delivery.

Even though the early introduction of water was not associated with malnutrition in this study, most $(85.9 \%)$ of the respondents started giving water to their children when they were less 
than 6 months old. That means that they did not adhere to the WHO recommendation of not giving water to infant below 6 months. Few (14.1\%) of the children less than 6 months had not been given water. However, $46.8 \%$ of respondents reported giving their children water on the very first day of life, because they said that there was no milk in their breast.

Initiation of breastfeeding, exclusive breastfeeding, timely complementary feeding and bottle feeding were found to be associated with malnutrition. Concerning early initiation of breastfeeding, children who were initiated breastfeeding beyond day three were more likely to be wasted compared to those started breastfeeding on the first day (OR 1.78, 95CI 1.02-2.54). Furthermore, children who were not exclusively breastfed were more likely to be underweight as well as wasted [(OR 2.12, 95\% CI 1.43-2.58) and (OR 1.9, 95\%1.51-3.32)] respectively. Other factors such as; ever breastfed and still breastfeeding were not significantly associated with malnutrition in this study.

Regarding timely complementary feeding, children who were introduced complementary foods late in time were more likely to be underweight and wasted compared to those introduced complementary foods timely [(OR 1.59, 95\%CI 1.22-2.91) and (OR 1.4, 95\%CI 1.09-2.43] respectively. Again it was also found that children who never used bottle feeding were less likely to be stunted than bottle users (OR $0.83,95 \% \mathrm{CI} 0.39-0.96)$. Furthermore, children who were introduced complementary foods late after six months were more likely to develop underweight and wasting [(OR 1.59 95\% CI 1.22-2.92) and (OR 1.40 95\% $1.09-2.43$ )] respectively. Similarly, bottle feeding is an important variable which has shown a significant association with malnutrition. Current study showed that majority (56.8\%) of the mothers who give infant formula use bottle feeding to feed their infants. Again the study has also revealed that children who were not bottle fed were less likely to become stunted compared to those who were bottle fed (OR 0.83, 95\%CI 0.39-0.96).

\section{Government/Ministry of health}

\section{RECOMMENDATIONS}

- There is a need for intervention programs. The study revealed that $28.5 \%$ of the children under two are wasted however in UNICEF's 2007 report, it is stated that countries with $10 \%$ or more wasted under-fives require urgent response. Since $28.5 \%$ is much far from $10 \%$ there is the need for an intervention.

- The Ministry of Health in collaboration with other non-governmental agencies such as the UNICEF should conduct similar study from time to time to monitor the nutritional status of children under two years and the kind of feeding practices that their mothers use.

- There is the need for the Ministry of Health and non-governmental agencies to introduce an intervention of health education immediately. This can be done by specifically using interpersonal communication to get family members to understand the recommended infant feeding practices.

- A further study on the quality and quantity of food given to the children is very necessary. This will give a baseline data for an effective health education programme on complementary foods in the district. 


\section{Health workers}

- Midwives and nurses must help the mothers to initiate breastfeeding early (within 30 minutes after delivery) and must assist women who deliver through caesarean sections to initiate breastfeeding within the first one hour after delivery.

- The traditional birth attendants should be educated on the importance of early initiation of breastfeeding and they should also assist mothers to initiate breastfeeding early using interpersonal communication.

- Health workers should explain the meaning of exclusive breastfeeding to the mothers and discourage mothers from introducing artificial milk and water to the children below the age of 6 months during antennal and child welfare clinics.

- Again health workers should encourage mothers to introduce complementary foods when their children are 6 months old. This can be done during antenatal and child welfare clinics

- Health workers should educate mothers on the importance of eating fruits and encourage them to give their children fruits every day.

- Health workers should discourage mothers on bottle feeding by talking about it always at antenatal and child welfare clinics.

\section{Researcher and scientific community}

- Further research should be carried out on this study to strengthen and broaden these findings and obtain data base for effective planning and implementation of control programmes.

\section{References}

ACF (2006).The KAP Deyr: Wajid, Bakool, Bay and GEDO regions. Mogadishu: ACF

Allen, L. and Gillespie S. (2001).What Works? A Review of the Efficacy of Nutrition Interventions. ACC/SCN Nutrition Policy Paper No. 19. London: ADB Nutrition and Development Series \# 5.

Amal, G.H, Nkala K. Aweis, M. and Msuya, E. (2011) Approaching the transition to adulthood: Distinctive profiles of adolescents aging out of the child welfare system.Social Services Review, 81, 453- 484.

ANON (2004). Nutrition of young children and mothers in Tanzania: findings from the 2003 Tanzania demographic and health survey. USA, Measure DHS+ program.

Burke, J. Danial, K, Gerson, Y. Timson, D. (2015) Complementary feeding practices: Brooklyn, NY: Hang Loose Press.

Cernades, J.M., Nocada, G. and Barrera, L. (2013).Maternal and perinatal factors influencing the duration of exclusive breastfeeding during the first 6 months of life. Journal of Human Lactation19, 136-144.

Childinfo (2009) Feeding practices of young children and infants: Improving participation in child feeding. Clemens, L, G (2009) Weaning of young infants: Weaning process: London: Elsevier.

Dewey, R. (2003) Complementary feeding practices and appropriate foods for children under five years: Survey Report. USA: Washington Publisher.

Dirorimwe, C. (2007). Short training guide on trials of improved feeding (TIPs): Introduction and supporting the improvement of household food security, nutrition and livelihoods in Afghanistan (GCP/AFG/039/GER). Kabul: Nutrition Education Component of the Project.

Dubois S. and Girard, H. (2013).Nutritional status and risk factors of chronic malnutrition in children under five years of age in western city of Ethiopia. Addis Ababa: Addis Publishers.

Dubois, L. and Girard, M. (2013). Social determinants of initiation, duration and exclusivity of breastfeeding at the population level: The results of the longitudinal study of child development in Quebec. Toronto: Canadian Journal of Public Health 94, 300-30. 
Dahie, H. A., \& Heyle, A. A. (2017). The Influence of Feeding Practices On Nutritional Status of Children Less Than 2 Years In Heliwa District, Mogadishu. Advances in Social Sciences Research Journal, 4(17) 93-119.

WHO/UNICEF, G. Y. (2006) Global Strategy for Infant and Young Child Feeding.World Health Organization. Geneva.

WHO/UNICEFWHO/UNICEF (1990). The importance of breastfeeding: London: Elsevier.

Engle P. (2007). Care and Nutrition: Concepts and Measurements (IFPRI). London: Elsevier.

Engle, F. ( 2007) The optimal duration of exclusive breastfeeding: report of an expert consultation, Geneva, Switzerland, 28-30 March 2001. Geneva.

Faber, G. and Wenhold, R. (2007) The nutritional status of children in South Africa. Cape Town: South Africa. FSNAU.DB.(2007). FSNAU; FSNAU Technical Series Reports. Mogadishu: No Volumes 9-13

PAHO and WHO (2003) Guiding Principles for Feeding Non-Breastfed Children 6-24 Months of Age. Washington, DC.

Haschke, Y. (2000) Impact of micronutrient deficiencies on growth: The stunting syndrome. Ann NutrMetab, 2002:46, 8-17.

Ibrahimzadekar, H. (2012) Progress for Children: A world fit for Children Statistical Review. 4.

Ijarotimi, R. (2012) Infant feeding and nutritional status: the dilemma of mothers in rural Senegal. Eur J ClinNutr, 1995:179-188.

Kramer, D. Rayhan IM, Duncan, Lk, Mohamed, H. Shira, F. (2011) State of the World's Newborns.Washington DC. Saving Newborn Lives.

Lewis. N and Toby, MD (2006).Somali Cultural Profile from http://ethnomed. org/ ethnomed /cultures/somali/somali_cp.html.

Mark, M. (2005). BeletWene District Baseline Nutrition Assessment Draft. Save the Children- UK: Mogadishu: Save the Children.

Meyer, GS. (2012) Factors Causing Malnutrition among under five Children in Atlanta. World Health Organization. $\mathrm{MoH}$, Somalia (2005). Exclusive breastfeeding: Mogadishu: $\mathrm{MoH}$

Monique, S. Jeny S. and David M. (2010).Designing a Community -Based Nutrition Program using the Hearth Model and the Positive Deviance Approach: A Field Guide. Mogadishu: Save the Children

Montani A. and Omwega A. (2002).Food Utilization in Somalia. Mogadishu: FSNAU.

Oddy WH. (2001) Breastfeeding protects against illness and infection in infants and children: a review of the evidence.Breastfeed Rev 9: 11-18.

Oireri, B.O.(2006). End of Project Evaluation Report.Waajid District Primary Health Care Project. Mogadishu: World Vision Somalia.

Oireri, B.O.(2006). Breastfeeding in Africa and the Latin American and Caribbean region: the potential role of urbanization. J Trop Pediatr 40: 137-43.

Omanga P. and Okeyo, B. (2015).Household Livelihood Security: Unpublished article: Nairobi, Kenya.

PAHO (2003) Nutrition Assessment of children and women in Africa. Kigali: POM Publisher.

Pelletier, J., Robert, T., Gerson, H. and Fualta Y. (1994) The potentiating effect of malnutrition on child mortality: epidemiologic evidence and policy implications. Nutrition Reviews 52:409-15.

Roy, J. (2014). End program assessment of nutrition services: Last quarter: Nairobi: LLPT

Schnooyi et al. (2009) Impact of micronutrient deficiencies on growth: the stunting syndrome. Ann NutrMetab, 2002:46, 8-17.

Schnooyi J., Swach, K., Fahad, T. and Dagnal SG. (2009) Breastfeeding timing: Exclusive breastfeeding. London: Sons Publishers.

SCN (2013).Summary of guiding principles for complementary feeding of the breastfed child.United Nations System Standing Committee on Nutrition.A Periodic Review of Developments in International Nutrition. Geneva. No. 27: 19

Shields S., Ray SK, Weyn G. and Roben, D. Lartey, A. (2014) Young Child Feeding Practices and Child Nutritional Status in Rural Ghana. International Journal of Consumer Studies 31(4): 326-332. 
Silvers S. Sekonda G. Dewey, K. and Soras W. (2013) Nutritional status and risk factors of chronic malnutrition in children under five years of age in Aydin, a western city of Turkey.Turk J Pediatr.

The Sphere Project (2004).Humanitarian Charter for Minimum Standards in Disaster Response. London: Macmillan.

UNDP (2006).Millennium Development Goals (MDG) Report. Nairobi: UNDP.

UNDP (2015).Human Development Report 2015. United nations Development Fund, Somalia Country Office. Nairobi: Elsevier.

UNICEF (2004).Knowledge Attitude Behaviour and Practices (KABP) on HIV/AIDS and Sexually Transmitted Infections (STI) among Somalis. Survey Report. Mogadishu: UNICEF Somalia.

UNICEF (2007).Knowledge Attitude Behaviour and Practices (KABP) on HIV/AIDS and Sexually Transmitted Infections (STI) among Somalis.Survey Report. Mogadishu: UNICEF Somalia.

UNICEF (2008).Knowledge Attitude Behaviour and Practices (KABP) on child feeding among Somali women.Survey Report. Mogadishu: UNICEF Somalia.

UNICEF (2009).Complementary feeding practices and appropriate foods for children under five years: Survey Report. Geneva: Switzerland.

UNICEF (2015).Knowledge Attitude Behaviour and Practices (KABP) on child feeding among Somali women.Survey Report. Mogadishu: UNICEF Somalia.

UNICEF (1990) Nutrition and malnutrition: The conceptual frame of malnutrition: Washington DC: Brotherly Publishers.

Villegas H and Stuebe D. (2013) Delayed Breastfeeding Initiation Increases Risk of Neonatal Mortality. Pediatrics: Nairobi: Macmillan.

Wambui, M. (2005).Project Evaluation Report Middle Juba PHC - Somalia. Mogadishu: World Vision Somalia.

WHO (2008).Infant and young child feeding. Paris: Elsevier.

WHO (2009).Infant and young child feeding. Breastfeeding 